\title{
Impact of Happiness Classes on the Students Studying in Schools of the Municipal Corporation, Delhi, India
}

\author{
Anushka Gupta ${ }^{1}$, Harish Kumar Tyagi ${ }^{2 *}$ \\ ${ }^{1}$ Research Scholar, AIBAS, Amity University, Uttar Pradesh \\ ${ }^{2} \mathrm{Head}$, AIBAS, Amity University, Uttar Pradesh
}

\begin{abstract}
Aim: This paper aims to study the impact of happiness classes on the students studying in the Municipal Corporation of Delhi (MCD) schools of Delhi. The paper mainly studies the opinion of teachers, as well as, students towards happiness classes and its relation to the academic achievement of the students.

Methodology: 25 teachers and 25 students of MCD were selected randomly for the data collection. Inventory on measuring the opinion of teachers about happiness classes and inventory on measuring the opinion of students about happiness classes were prepared by the researcher and were administered on the selected sample.
\end{abstract}

ConclusionFindings: This study reveals that the opinion of male and female teachers, as well as, students do not differ significantly with respect to the happiness classes and happiness of students is related to some extent to the academic accomplishments of students.

Keywords: Academic accomplishment, Happiness curriculum, MCD schools, Students in happiness classes.

Journal of Teacher Education and Research (2020). DOI: 10.36268/JTER/15103

\section{INTRODUCTION}

All over the world education system is under fire in all sections of the society, mainly because it is not delivering the goods properly, the emphasis has always remained on memorization, instead of the construction of knowledge by the learners. This is one of the reasons why happiness among the students regarding their studies has got lost with time and studies are seen as a burden and not a source of knowledge. Thus, the qualitative development of the pupils remains hampered even up to adulthood. That is why the majority of students are found to be slow learners or educationally backward. Hence, it is very important to develop or enhance the present curriculum so that the teachers can carry out the teaching-learning process more productively.

The National Curriculum framework 2005 (NCF) recognized the fact made by the Yash Pal Committee, as well as, by National Curriculum Framework for School Education (NCFSE - 2000), that "we should try to minimize the emphasis on holding of information without comprehension. Given that syllabus framers and textbooks writers need to choose what to include from a mass of relevant information, the effort should not be just to convey as many facts as possible. Instead, a focus on concepts and the ability to analyze sociopolitical realities should be stressed."

All children have unique characteristics when they are born. They are brought up in a different environment. The environment, in which a child grows up today is unreliable and unbalanced, with a constant change in social and economic aspects, making it very hard to imagine what the future will hold for such children. Many children take birth $\overline{\text { Corresponding Author: Dr. Harish Kumar Tyagi, Head, AIBAS, Amity }}$ University, Uttar Pradesh, E-mail: hkumar2@amity.edu

How to cite this article: Gupta, A. \& Tyagi, H.K. (2020). Impact of Happiness Classes on the Students Studying in Schools of the Municipal Corporation, Delhi, India. Journal of Teacher Education and Research, 15(1):11-14.

Source of support: Nil

Conflict of interest: None

within the four-walled buildings, whereas, many others grow up in very difficult conditions with no or little nutrition for the body and the mind, some not even having seen a book or a toy until they go to school. In both cases, there is either an over stimulus or scarcity in these areas with our students leading to various psychological crunch that is turning out of control.

Thus, the schools in India need to apply a curriculum, which not only promotes development in specific fields, like cognition, language, literacy, numeracy, and the arts but also is concerned with the health and happiness of the students. Therefore, a combination of forming abilities in scholastic areas of language, science, mathematics, and other school subjects with huge importance placed on co-scholastic skills of mindfulness, self-awareness, critical thinking, reflection, and inner stability, seems to be the need of the hour. Against this background, the need to raise and prepare the future citizens who are attentive, aware, roused, imagined, and aware of their identity with wings or resources that can help them grow and develop in this unpredictable world seems to be more important. Therefore, the present study was an

(0) The Author(s). 2020 Open Access This article is distributed under the terms of the Creative Commons Attribution 4.0 International License (http://creativecommons. org/licenses/by/4.0/), which permits unrestricted use, distribution, and non-commercial reproduction in any medium, provided you give appropriate credit to the original author(s) and the source, provide a link to the Creative Commons license, and indicate if changes were made. The Creative Commons Public Domain Dedication waiver (http://creativecommons.org/publicdomain/zero/1.0/) applies to the data made available in this article, unless otherwise stated. 
attempt to study the impact of the happiness classes on the primary level students studying in MCD schools of Delhi, and the impact of happiness as a factor on the academic achievement of the students.

The challenges faced by the school system have gone far away from the poor learning standards and low academic results. Research conducted by Kumar et al. (2013) found that India has reached a stage of worrying suicide rates among students. Besides the challenges of learning and achievement, students come to school with various stressors caused by a variety of reasons, such as, family-system conflicts, peerinteraction conflicts, socio-cultural components, and weaknesses to physical and mental health risk factors. The research revealed that there are 26 suicides reported every 24 hours due to reasons, such as, drugs, broken families, and fights with friends and breakups. Continued exposure to such stressors leads to a long term impact on physiological and emotional health, which profoundly affects a child's learning and development.

As per the World Happiness Report 2017, our country is the least happy country in the world. It is ranked 122 among 155 countries in the international position and has further fallen to the position of 133 in the World Happiness Report of 2018. This presents a major challenge for society and families on how children should be nurtured and prepared. Mistrust, insecurity, impulsivity, social comparisons, over achievements, lack of sense of identity, and low selfesteem can lead to distorted and imbalanced growth, the consequences of which could be dreadful and far-reaching.

This forces us to re-think the purpose of education, which is more than merely improving the student's performance in the scholastic area. In today's times, we constantly struggle hard to achieve the best of everything but the factor of happiness remains missing. But, if one learns how to be happy with oneself, stress levels may reduce inevitably and one can develop a deeper understanding of not only of themselves but also that of others. Accordingly, a happy human being with deeper understanding tends to have a greater tendency for self-discovery and lower self-deceit.

The "happiness curriculum" is designed in such a way that its primary focus is on the process rather than the outcome. The results of the process might take time to appear. Each student has a different and unique journey in his life, which makes him a productive member of society. The assessment should be conducted with meekness and decency and should be less quantitative and more qualitative in manner. As a result, it makes one wonder about the unspoken message that gets communicated. The students are unhappy and examinations and their textbooks are causes of their unhappiness. They will become happy if these reasons are exterminated.

Therefore, the "happiness curriculum" tries to establish "happiness" as a separate subject, which includes its own methods, like mental exercises, idealistic and realistic stories, discussion based on activities, reflection by students, and non-graded examinations.

\section{Methodology}

This study is a survey type of research. For the sample, 25 students from primary classes and 25 teachers teaching the primary class students from five MCD schools were selected randomly and a self-constructed toll was used to collect the data.

\section{Hypothesis}

The following hypothesis was formulated and statistically tested.

- There is a significant difference among the male and female teachers in respect of student-related factors.

- There is a significant difference in the opinion of male and female teachers in relation to teacher-related factors.

- There is a significant difference in the opinion of male and female teachers in relation to curriculum transaction-related factor.

- There is a significant difference in the opinion of male and female teachers in relation to parents related factor.

- There is a significant difference in the opinion of male and female teachers in relation to personal factors.

- There is a significant difference in the opinion of male and female teachers in relation to teacher-related factor.

- There is a significant difference in the opinion of male and female teachers in relation to curriculum transaction-related factor.

HO1-There is a significant difference among the Male and Female Teachers in respect of Student-Related Factors

Table 1 shows the mean obtained by male and female teachers in respect of student-related factors. As can be seen, female teachers obtained lesser mean minutely in comparison to male teachers. Further what can be seen from Table 1 is that the value of " $t$ " is found to be not significant. Hence, it may be inferred that there is no statistically significant difference between the two compared groups in relation to the student-related factor. This result rejected the hypothesis that there may be a significant difference between

Table 1: Significance of " $\mathrm{t}$ " for compared groups in respect of student-related factors

\begin{tabular}{llllllll}
\hline Factor & Compared group & $N$ & Mean & SD & Df & t value & Result \\
\hline Student related & Male teachers & 8 & 41.25 & 3.33 & \multirow{2}{*}{23} & $0.0122^{*}$ & Not significant \\
factors & Female teachers & 17 & 41.23 & 4.02 & & & \\
\hline
\end{tabular}

NOTE: ${ }^{*} p<0.01$ 
male and female teachers with respect to student-related factors. Henceforth, it can be concluded that the opinion of male and female teachers does not differ in relation to student-related factors.

HO2-There is a significant difference in the Opinion of Male and Female Teachers in relation to Teacher-Related Factor

Table 2 shows the mean obtained by male and female teachers in respect of teacher-related factors. As can be seen, female teachers obtained lesser mean minutely in comparison to male teachers. Further, what can be seen from Table 2 is that the value of " $\mathrm{t}$ " is found to be not significant. Hence, it may be inferred that there is no statistically significant difference between the two compared groups in relation to the teacher-related factor. This result rejected the hypothesis that there may be a significant difference between male and female teachers with respect to teacher-related factors. Henceforth, it can be concluded that the opinion of male and female teachers does not differ in relation to teacher-related factors.

HO3-There is a significant difference in the Opinion of Male and Female Teachers in relation to Curriculum TransactionRelated Factor

Table 3 shows the mean obtained by male and female teachers in respect of curriculum transaction-related factors. As can be seen, female teachers obtained lesser mean minutely in comparison to male teachers. Further, what can be seen from Table 3 is that the value of " $\mathrm{t}$ " is found to be not significant. Hence, it may be inferred that there is no statistically significant difference between the two compared groups in relation to the curriculum transaction-related factor. This result rejected the hypothesis that there may be a significant difference between male and female teachers with respect to curriculum-related factors. Henceforth, it can be concluded that the opinion of male and female teachers does not differ in relation to curriculum transaction-related factors.

HO4-There is a significant difference in the Opinion of Male and Female Teachers in relation to Parents-Related Factor

Table 4 shows the mean obtained by male and female teachers in respect of parents related factors. As can be seen, female teachers obtained lesser mean minutely in comparison to male teachers. Further, what can be seen from Table 4 is that the value of " $t$ " is found to be non-significant. Hence, it may be inferred that there is no statistically significant difference between the two compared groups in relation to the parentsrelated factor. This result rejected the hypothesis that there may be a significant difference between male and female teachers with respect to parent-related factors. Henceforth, it can be concluded that the opinion of male and female teachers does not differ in relation to parents-related factors.

HO5-There is a significant difference in the Opinion of Male and Female Teachers in relation to Personal Factors

Table 5 shows the mean obtained by male and female students in respect of personal related factors. As can be seen, female students obtained lesser mean minutely in comparison to male students. Further, what can be seen from Table 5 is that the value of " $\mathrm{t}$ " is found to be non-significant. Hence, it may be inferred that there is no statistically significant difference between the two compared groups in

Table 2: Significance of " $t$ " for compared groups in respect of teacher-related factors

\begin{tabular}{|c|c|c|c|c|c|c|c|}
\hline Factor & Compared group & $N$ & Mean & $S D$ & $D f$ & tvalue & Result \\
\hline \multirow[t]{2}{*}{ Teacher related factor } & Male teachers & 8 & 17 & 2.26 & \multirow{2}{*}{23} & \multirow{2}{*}{$0.9477^{*}$} & \multirow{2}{*}{ Not significant } \\
\hline & Female teachers & 17 & 16.17 & 1.94 & & & \\
\hline
\end{tabular}

NOTE: ${ }^{*} p<0.01$

Table 3: Significance of " $\mathrm{t}$ " for compared groups in respect of curriculum transaction-related factors

\begin{tabular}{llllllll}
\hline Factor & Compared group & $N$ & Mean & $S D$ & Df & t value & Result \\
\hline Curriculum transaction- & Male teachers & 8 & 47.75 & 4.2 & & \multirow{2}{*}{$1.5885^{*}$} & Not significant \\
related factor & Female teachers & 17 & 44.88 & 4.22 & & & \\
\hline
\end{tabular}

NOTE: ${ }^{*} p<0.01$

Table 4: Significance of " $\mathrm{t}$ " for compared groups in respect of parents-related factors

\begin{tabular}{llllllll}
\hline Factor & Compared group & $N$ & Mean & Standard deviation & Degree of freedom & t value & Result \\
\hline Parents-related factor & Male teachers & 8 & 8.12 & 1.35 & 23 & \multirow{2}{*}{$0.7882^{*}$} & Not significant \\
& Female teachers & 17 & 7.64 & 1.45 & & & \\
\hline
\end{tabular}

NOTE: ${ }^{*} p<0.01$

Table 5: Significance of " $\mathrm{t}$ " for compared groups in respect of personal factors

\begin{tabular}{llllllll}
\hline Factor & Compared group & $N$ & Mean & SD & Df & t value & Result \\
\hline Personal factors & Male students & 13 & 34 & 4.339 & 23 & $0.0977^{*}$ & Not significant \\
& Female students & 12 & 33.83 & 4.195 & 23 & & \\
\hline
\end{tabular}

NOTE: ${ }^{*} p<0.01$ 
Impact of Happiness Classes on the MCD School Students

Table 6: Significance of " $t$ " for compared groups in respect of teacher-related factors

\begin{tabular}{llllllll}
\hline Factor & Compared group & $N$ & Mean & Standard deviation & Degree of freedom & t value & Result \\
\hline Teacher related & Male students & 13 & 11.46 & 1.265 & 23 & $1.345^{*}$ & Not significant \\
factor & Female students & 12 & 12.16 & 1.337 & & & \\
\hline
\end{tabular}

NOTE: ${ }^{*} p<0.01$

Table 7: Significance of " $\mathrm{t}$ " for compared groups in respect of curriculum transaction-related factors

\begin{tabular}{llllllll}
\hline Factor & Compared group & $N$ & Mean & $S D$ & $D f$ & $t$ value & Result \\
Curriculum transaction-related & Male students & 13 & 21.69 & 2.323 & & & \multirow{2}{*}{ Not significant } \\
factors & Female students & 12 & 20.58 & 2.678 & & $1.1095^{*}$ & \\
\hline
\end{tabular}

NOTE: ${ }^{*} p<0.01$

relation to the personal-related factor. This result rejected the hypothesis that there may be a significant difference between male and female students with respect to personal related factors. Henceforth, it can be concluded that the opinion of male and female students does not differ in relation to personal-related factors.

HO6-There is a significant difference in the Opinion of Male and Female Teachers in relation to Teacher-Related Factor

Table 6 shows the mean obtained by male and female students in respect of teachers-related factors. As can be seen, female students obtained lesser mean minutely in comparison to male students. Further, what can be seen from Table 6 is that the value of " $\mathrm{t}$ " is found to be non-significant. Hence, it may be inferred that there is no statistically significant difference between the two compared groups in relation to the teacher-related factor. This result rejected the hypothesis that there may be a significant difference between male and female students with respect to teacher-related factors. Henceforth, it can be concluded that the opinion of male and female students does not differ in relation to teacher-related factors.

HO7-There is a significant difference in the Opinion of Male and Female Teachers in relation to Curriculum TransactionRelated Factor

Table 7 shows the mean obtained by male and female students in respect of curriculum transaction-related factors. As can be seen, female students obtained lesser mean minutely in comparison to male students. Further, what can be seen from Table 7 is that the value of " $t$ " is found to be non-significant. Hence, it may be inferred that there is no statistically significant difference between the two compared groups in relation to the curriculum transactionrelated factor. This result rejected the hypothesis that there may be a significant difference between male and female students with respect to curriculum transaction-related factors. Henceforth, it can be concluded that the opinion of male and female students does not differ in relation to curriculum transaction-related factors.

\section{Conclusion}

Education is not only responsible to provide the reading and writing skills to the learners but it goes beyond this and helps learners in providing them value education, making them up-to-date, and opening their horizons of thinking. It is well understood that quality education has to make the learners competitive in the present day. It has also been experienced that all over the world the present education system is under fire in all sections of the society, mainly because it is not delivering the goods properly. The emphasis has always remained on memorization. Thus, the qualitative development of the pupils remains helpless even up to adulthood, and the education process is seen as a burden or source of stress by the students. That is why a majority of students are unhappy and were found below their mental level because of the stigma of memorizing information and getting good grades. Hence, it is very essential to develop some insights into the achievement of the students, and how the achievement of students is related to various other factors, such as, happiness, stress, games, etc. Undoubtedly, "happiness classes" under the "happiness curriculum" implemented by the Delhi government is a progressive and also qualitative sign in the development of learners, and in the coming years, its result will be seen in the form of students genuinely interested and happy to learn, rather than learning to only pass and get good grades.

\section{References}

Kumar, S., Verma, A. K., Bhattacharya, S., \& Rathore, S. (2013). Trends in rates and methods of suicide in India. Egyptian Journal of Forensic Sciences, 3(3), 75-80.

National Council of Educational Research and Training (2005). National Curriculum Framework for School Education. New Delhi: NCERT.

Helliwell, J. F., Huang, H., \& Wang, S. (2017). The Social Foundations of World Happiness. World Happiness Report.

Aristotle, (Edited and Translated by R.Crisp) (2000). Nichomachean Ethics. Cambridge: Cambridge University Press. 